\title{
Mobile Governance based on WiMAX Connectivity for Rural Development in India
}

\author{
Mrs. Kalpana Chaudhari \\ Shah And Anchor Kutchhi Polytechnic Mumbai, India. \\ isdrklc@hotmail.com \\ Dr Mrs. Upena D Dalal \\ Sardar Vallabhbhai National Institute Of Technology, Surat, India \\ Upena_Dalal@Yahoo.Com \\ Mr. Rakesh Jha \\ Sardar Vallabhbhai National Institute Of Technology, Surat, India \\ Jharakesh.45@gmail.com
}

\begin{abstract}
The research work aims to explore the nature, role and relevance of the wireless technologies such as WiMAX connectivity for rural area of Jalgoan district, India. It focuses on development of the WiMAX(Worldwide Interoperability for Microwave Access) network model using OPNET MODELER 14.5 and observe overall performance with fixed, mobile node with two base station. The model is Proposed to connect 50GKC (nodes), which are distributed all over coverage area of Jalgoan district using WiMAX connectivity. The 50 number of GKC are proposed to work in between $783 \mathrm{Gram}$ panchayats of Jalgoan district which is supposed to run with the support of Gram panchayat head. The scope of WiMAX is to provide last mile wireless broadband access for fixed and mobile users as an alternative to the wire line DSL and cable access. The physical and MAC layer of this technology refer to the IEE802.16e standard which supports five different data delivery service classes that can be used in order to satisfy QOS requirement of different applications such as VOIP, videoconference, FTP, web etc. The work is divided in three scenarios (network model), each scenario consist of different number of nodes with two BS and performance is observed with audio and video application such as VOIP and MPEG .All simulation results based on optimized network and area considered between two base station. The work provide the high speed wireless connectivity platform to build Electronic Governance project in Jalgoan district.
\end{abstract}

Index Terms - ICTs; E. Governance; rural development; WiMAX ; OPNET modeler

\section{I .OBJECTIVE}

1. To identify the critical parameters in Electronic Governance for rural development with reference to Different services.

2. To disseminate the information required for Electronic Governance for planning, development Management of different rural services.

3. To Simulate network model based on WiMAX technology.

\section{II .WHAT IS E. GOVERNANCE}

E-governance[1][4] is defined as "the application of information and communication technologies to transform the efficiency, effectiveness, transparency and accountability of informational and transactional exchanges with in government, between govt. and govt. agencies of National, State, Municipal and Local levels, citizen and businesses, and to empower citizens through access and use of information."

\section{WHAT IS RURAL AREA AND URBAN AREA[2]}

The rural areas are the human settlements which do not conform to the definition of the urban areas. According to 1991 Census the area which meet one or more of the following criteria are classified as urban areas.

- All places with a Municipality, Municipal Corporation, Cantonment Board or Notified Town area Committee etc. 
- All other places which satisfy the following criteria

(a) A minimum population of 5000;

(b) At least $75 \%$ of male working population engaged in non-agricultural pursuits and

(c) A population density of at least 400 persons per sq.

$\mathrm{km}$.

- Areas which do not satisfy the conditions under (a) and (b) above are classified as rural.

\section{RURAL MARKET ENVIRONMENT [2]}

1. Low population spread over a large geographical areas and difficult terrain

2. Primarily agricultural economy

3. Poor infrastructure like, roads, electricity, water etc

4. Heavy investments with low return

5. Poor facilities for health, education, entertainment etc.

6. Lower levels of literacy

7. Low per Capita Incomes/Economic backwardness.

8. Ignorance of Custodian about system, and

9. Misuse of components

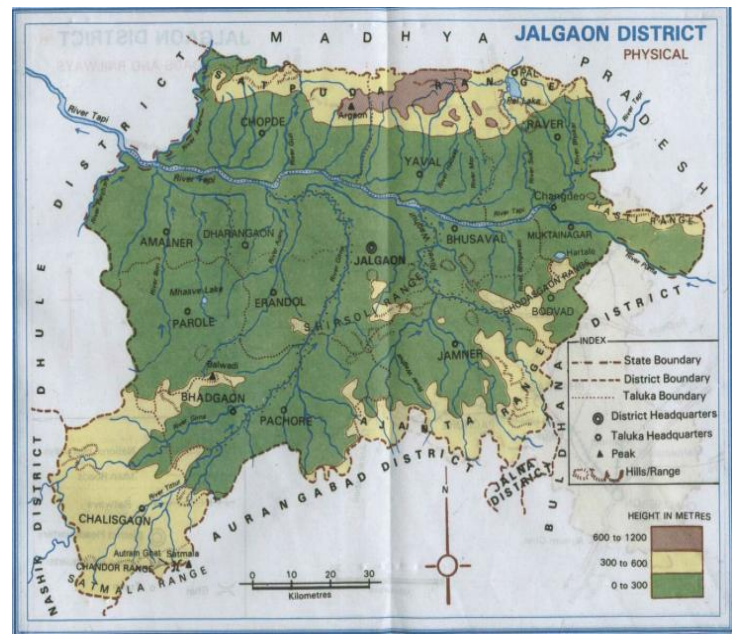

Fig1 Jalgoan district map

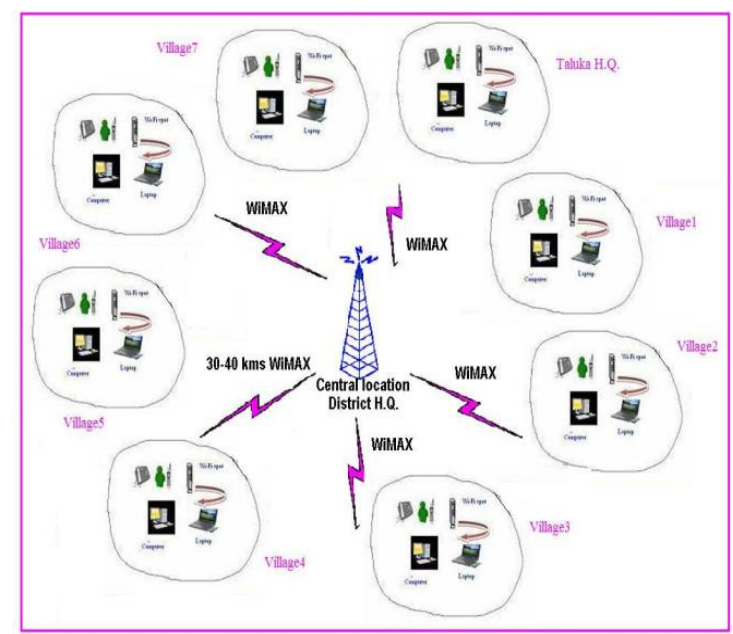

Fig.2 WiMAX model for Jalgoan District

\section{ICT INFRASTRUCTURE FOR RURAL E- GOVERNANCE APPLICATIONS}

The typical ICT infrastructure adopted by most of the rural applications is presented in the Fig2 based on WiMAX technology .The rural ICT solutions are normally offered through internet portals hosted on a delivery web server to provide access to the citizens through inexpensive internet medium. The information flow between the delivery server and the other departments is accomplished through Intranet / LAN connectivity with servers of those departments (if exist). Often, due to non-computerization of back-end systems, the transactions are manually exchanged and response data is keyed in manually through the nodes on the delivery server. It may be noticed that the end-to-end connectivity between the central service providers (district administrations, cooperative unions etc.) and the citizens are accomplished through a number of stages involving several agencies/stake holders. These stages, the technologies and agencies/stake holders should involve in offering the different services in rural area .

In this paper We considered case of Jalgoan district from Maharashtra state of India. The District map is shown in Fig 1.The Jalgoan district is having 15 Talukas, 1498 villages and 767 Gram panchayats. The geographical 
information is given in table1. The district head quarter (DHQ) can connect to all 15 Tahsil Head quarter (THQ) and also all villages should connect to THQ and DHQ to access the information.

The village panchyat should start Gram pancahyat knowledge centre (GKC) to coordinate with rural citizen between DHQ and THQ using WiMAX technology to utilize the public services in all types of sectors. E. Governance Model using WiMAX is shown in Fig. 2. This model is designed to increase the economical growth of rural population, to improve the leaving standards of rural area, to empower rural families with new knowledge and skills, to make life secure and healthy the local population should be willing to make use of GKC, so that the long-term economic sustainability of the program is ensured. The local communities should be able to run the canters when the implementing agency moves to other regions. The GKC and THQ, DHQ should act as a rural library and much more. Each hub centre may cover whole taluka, all villages (within a radius of $50 \mathrm{~km}$ ). The GKC consist of computers/laptop, one scanner, land line phone, cell phone, web cameras, internet facility, one printer, one digital camera, solar backup facility, etc. The GKC should be located in a public place and not to be associated with one group or caste. Allowed everyone to take part. Each THQ and DHQ should have two-way communication with GKC. With the help of this project data base will be created in case of agriculture Land/property ,pet records, house record, property transfer, property tax, gender record ,literacy record ,Birth record, marriage record, death record

\section{SOCIAL BENEFITS}

Through this model rural women will come to know women's rights, procedures to be followed in lodging a complaint, land related issues, vocational course details for women, health issues, social issue ,counselling, various marketable cottage products, etc. Panchayat matters ,births, deaths, utility connection (water, electricity etc.), property transfer, tax rules, tax payments, license and concessions, permits Tourism and transport ,room availability/ booking, booking of long distance bus is possible by involving the stake holder in respective subject. By arranging wireless communication /video conference with different experts in case agriculture/public health doctors /veterinary doctors /counselor the rural people can get help through the GKC. It is also possible for vaccination schedule, especially pregnant women and infants, family planning, medicines, ambulance services and transportation, hospital and primary centers information, blood bank, live saving drugs, doctor's database, and appointment with doctors, tele-health, and medicines management system for rural public health centre. For high speed data transfer and wireless broad band connectivity the WiMax is very good solution .

\section{VII.SIMULATION SETUP}

For the simulation of network model the OPNET modeler 14.5 is used. OPNET is a network technology development environment that allows to design, study communication networks, devices, protocols and applications[8][9]. In simple terms it allows to simulate elements of a computer network in order to investigate and how they will react to different circumstances without the need to physically construct them. Here, the three scenarios for fixed node and mobile node with two BS, we choose the statistics for the models and simulate model. In this research, The work is divided in three scenario. Here two types of MAC layer quality of service (QOS) are used and they are Unsolicited Grant Service (UGS) and Real time polling Service ( rtPS) having application of Voice over IP (VoIP) and Moving Picture Experts Group (MPEG) respectively. Also the traffic priority for UGS is high as compared to rtPS. In each scenario the number of fixed nodes (Fixed Subscriber Stations) and Mobile nodes (Mobile Subscriber Stations) are different. To cover more nodes or if nodes are outside 
the coverage area more than one BS are required. Through different scenario, the comparison of throughput and delay with respect to time is observed. All the parameters are set as per table2

In OPNET Modeler the three scenarios crated as below

Scenario 1: In first Scenario model Fig4 (a) the performance is observed with one Server, Two BS and 10 clients. (consist of 5 fixed nodes and 5 mobile nodes with 2 base station BS1 and BS2 )

Scenario 2: In Second Scenario model Fig 4(b) the performance is observed with one Server, Two BS and 25 clients (consist of 12 fixed nodes and 13 mobile nodes with 2 base station BS1 and BS2 )

Scenario 3: In third Scenario model Fig 4 (c) the performance is observed with one Server, Two BS and 50 clients. (consist of 25 fixed nodes and 25 mobile nodes with 2 base station BS1 and BS2)

Table1 Geographical information of Jalgoan District

\begin{tabular}{|l|l|}
\hline Geographical Area & 11,765 SqKm. \\
\hline Jalgaon City & $\begin{array}{l}68.78 \text { sqkm (Source - Jalgaon } \\
\text { City Municipal Corporation) }\end{array}$ \\
\hline $\begin{array}{l}\text { Taluka/Tahsil in } \\
\text { Jalgaon district }\end{array}$ & 15 \\
\hline $\begin{array}{l}\text { Total Villages, Cities } \\
\text { and places in Jalgaon } \\
\text { District }\end{array}$ & 1498 \\
\hline $\begin{array}{l}\text { Total number of Gram } \\
\text { Panchayats in Jalgaon } \\
\text { District }\end{array}$ & $\begin{array}{l}\text { Commission's } \\
01 / 05 / 2005)\end{array}$ \\
\hline $\begin{array}{l}\text { Population statistics } \\
\text { Literacy(As per census } \\
\text { 2001) }\end{array}$ & $\begin{array}{l}76.06 \% \quad \text { (Male - } \\
\text { Female - 64.95\%) }\end{array}$ \\
\hline
\end{tabular}

\begin{tabular}{|l|l|}
\hline Computer Literacy & $57 \%$ \\
Computer usage ratio & 47 per 100 \\
\hline
\end{tabular}

\section{RESULTS}

Here the global analyses of all the scenarios are done and the comparison of throughput and delay are shown in Fig5 and Fig7. Here as the number of nodes increases the throughput of complete network will get improved since more number.

Fig 5 Shows Comparison of the result between delay vs. Simulation time ,here Scenario 1,2 3 has minimum delay about $0.05 \mathrm{sec}$ at initial stage and at final stage Scenario 1 has $0.3 \mathrm{sec}$, Scenario2 has $0.6 \mathrm{sec}$ and Scenario3 has $1.1 \mathrm{sec}$.

Fig6 shows the Comparison of load (packets/sec) throughout the network in each scenario. Here Scenario 1 has lowest load in between $15,000,000$ to $20,00,000$ bits / sec, scenarios 3 has the highest load in between $40,000,000$ to $45,000,000$ bits / sec and scenario 2 has near about 30,000,000 bits / sec load

Fig 7 shows average throughput of all three scenarios with simulation time. Scenario1 has throughput from 0 to $5,500,500 \mathrm{bits} / \mathrm{sec}$, sceanario2 has lowest throughput from 0 to $4,500,000 \mathrm{bits} / \mathrm{sec}$ while scenario 3 has the highest throughput from 0 to $6,000,000 \mathrm{bits} / \mathrm{sec}$.

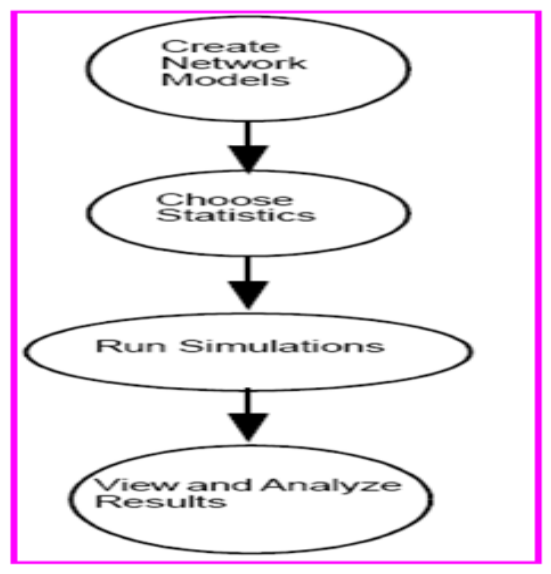

Fig 3 Work flow 
Table2 simulation parameters

\begin{tabular}{|c|c|}
\hline $\begin{array}{l}\text { Efficiency } \\
\text { mode }\end{array}$ & Mobility and ranging Enabled \\
\hline $\begin{array}{l}\text { AC service } \\
\text { class } \\
\text { Definition } \\
\text { (QOS) }\end{array}$ & $\begin{array}{c}\text { UGS } \\
\text { Eg. VOIP ( IP telephony) } \\
\text { rtps } \\
\text { Eg. MPEG } \\
\text { (high rewsolution video) }\end{array}$ \\
\hline $\begin{array}{c}\text { Modulation } \\
\text { technique }\end{array}$ & Wireless OFDMA \\
\hline $\begin{array}{l}\text { Number of } \\
\text { Subcarrirs }\end{array}$ & 2048 \\
\hline Band width & $20 \mathrm{MHz}$ \\
\hline $\begin{array}{l}\text { Duplexing } \\
\text { Technique }\end{array}$ & TDD \\
\hline
\end{tabular}

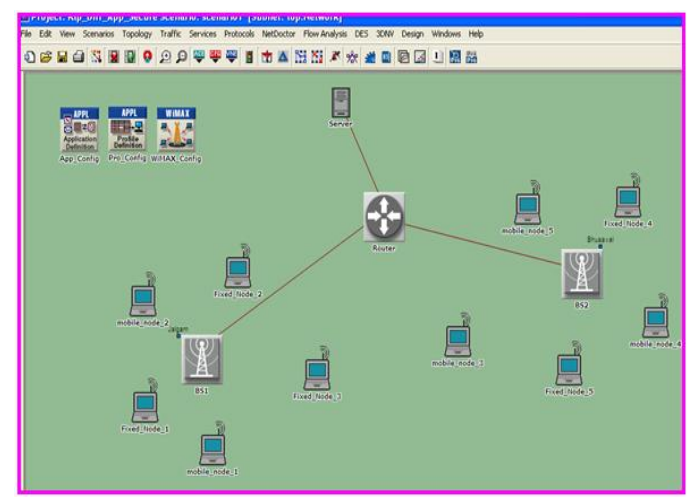

Fig4 (a) Scenario1 (Network with optimal BS with 10 clients)

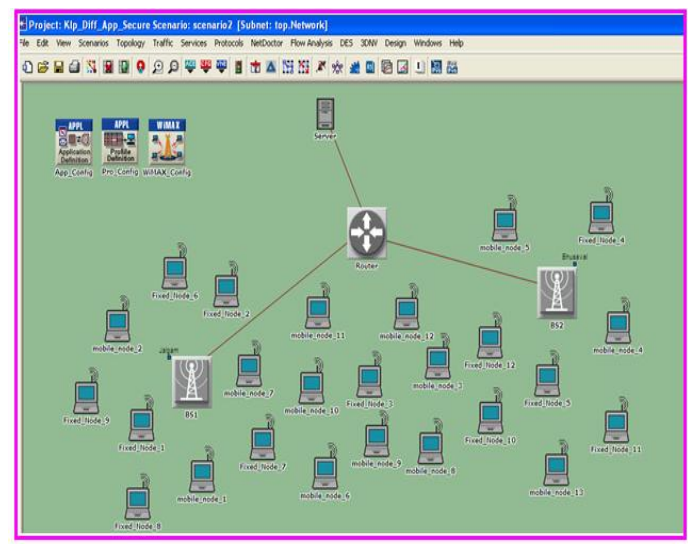

Fig 4 (b)Scenario 2 (Network with optimal BS with 25 clients)

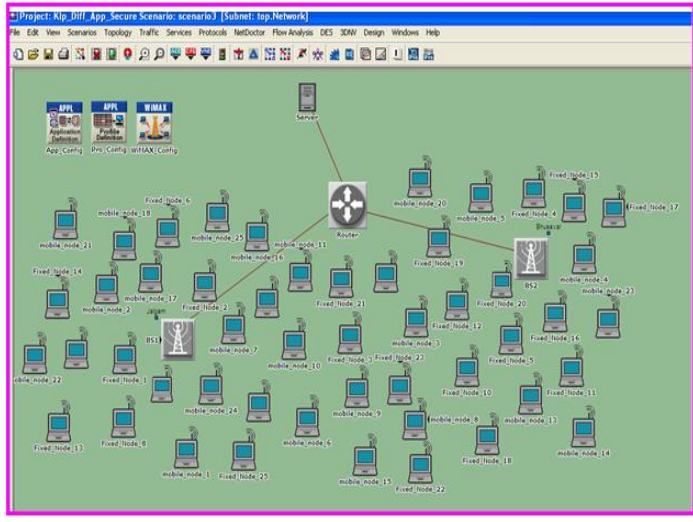

Fig.4 (c) Scenario 3 (Network with optimal BS with 50 clients)

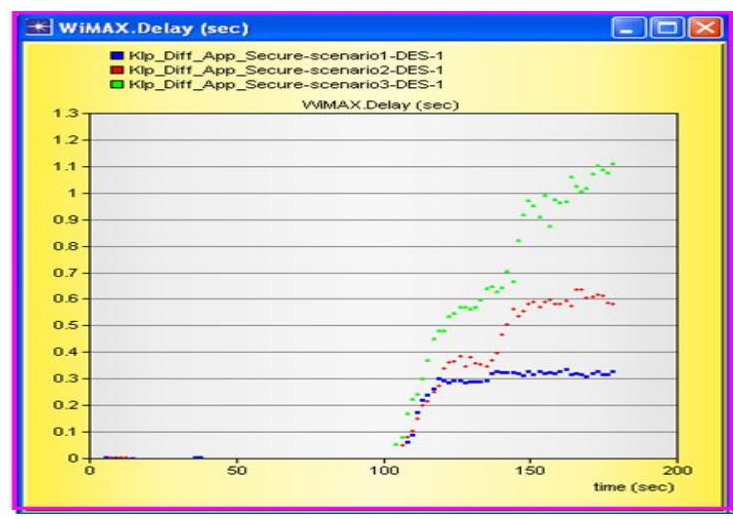

Fig 5 Delay vs Simulation Time

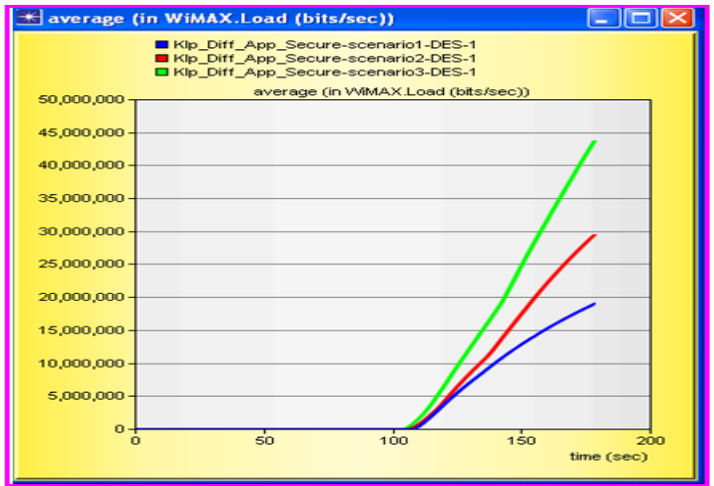

Fig 6 load ves Simulation 


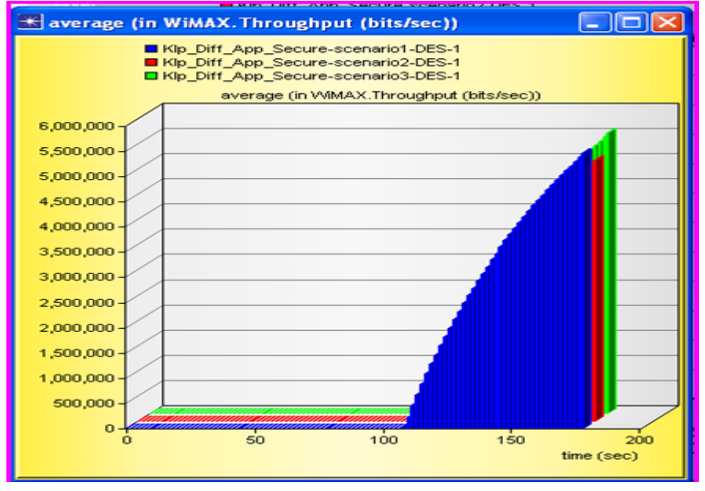

Fig 7 Throughput vs Simulation Time

\section{VIII.CONCLUSION}

WiMAX is satisfactory solution for rural connectivity and it is a new standards-based wireless technology gaining rapid acceptance around the world. It is capable of delivering broadband Internet service and extending services like Internet telephony throughout India without major disruption to transportation and other services. Unlike wired solutions, it requires no blocking of traffic, no digging miles of trenches for laying telecommunication cables, no ruining blocks of roads to provide Internet services, no waiting on massive infrastructure build-out projects, and no overhanging cables that could snap anytime. WiMAX offers a fast, affordable, convenient solution to India's widespread .Internet access required to start e-governance for rural administration, agriculture development and management and also for educational development. The performance analysis with loads, with location based with Video Application and QoS WiMAX delivers greater throughput.

If number of nodes in the network increases then throughputs of the network increases and delay of network will reduces in proportionally and vice versa The WiMAX is really good replacement for existing network. The work will be helpful to deploy WiMAX system within country and out of country. It is found that OPNET MODELER 14.5 is suitable to test the network. It would also ensure by getting WiMAX broad band connectivity will increase the work efficiency in rural area in all sectors.

\section{REFERENCES}

[1] Backus Michiel (no. 3, April 2001) research report, E- Governance and Developing Countries

[2] Bharat sanchar Nigam limited (BSNL) ,2005 presentation in west Bengal, Urban And Rural context ,BSNL Services in rural area of west Bengal

[3] Dalal Upena (2009) Oxford university press published the book Wireless communication'

[4] Jain Pelvic Shailendra C and sharma Sushil S. (2003) E-Government and E-Governance: Definitions/Domain Framework and Status around the World

[5] Technology@Intel Magazine WiMAX in India: Opening New Frontiers Through Broadband Connectivity

[6] Electronics for you, March2008, pp-157, WiMAX makes the most sense in rural India

[7] Abhijit Lele, , Mayank Raj, , Debabrata Providing Voice Connectivity to Rural India Using WiMAX: Issue sand Solution

\section{http://www.dritte.org/nsdr07/files/papers/s1p2.pdf}

[8] Shaswar Baban, MSc degree in the Department of

Electronic Systems at the University of Westminster report on "Design and Implementation of a Scheduling Algorithm for t he IEEE 802.16e (Mobile WiMAX)

Network ",September 2008

www.mbifoundation.com/media/43203/Shaswar-

Baban-dissert...

[9] Tanjila Farah ,Rajvir Gill project report on Comparison of WiMAX and ADSL by Streaming Audio and Video Content Spring 2011 www.sfu.ca/ tfarah 
Mrs. KalpanaChaudari Lecturer, Shah And Anchor Kutchhi Polytechnic, Mumbai ,India, also doing social work through NGO, Institute for sustainable development and research, Recently completed M.Tech(Electronics) from Sardar Vallabhbhai National Institute Of Technology, Surat, India

Dr.Mrs. Upena D. Dalal Ph.D. and Associate Professor in Sardar Vallabhbhai National Institute Of Technology, Surat, India.

Mr.Rakesh Jha Ph.D candidate, Sardar Vallabhbhai National Institute Of Technology, Surat, India. 